\title{
Interrogando espaços de alteridade: em direção a uma pedagogia pós-crítica para o drama e o teatro aplicados ${ }^{1}$
}

\section{Interrogating spaces of otherness: Towards a post- critical pedagogy for applied drama and theatre}

Kennedy C. Chinyowa ${ }^{2}$

Tradução: Beatriz Ângela Vieira Cabral ${ }^{3}$ 


\section{Resumo}

Enquanto os expoentes da pedagogia crítica argumentam que ela é um enquadramento apropriado para desafiar os discursos dominantes que buscam perpetuar as relações de poder opressivas e desigualdades sociais, outros começam a contra-argumentar que ela ainda permanece uma "pedagogia do oprimido". Ao continuar a construir um "mundo" dividido em oposições binárias de raça, classe, gênero e etnias, a pedagogia crítica tende a encobrir relações mais complexas de poder nas quais estas categorias são fluídas em vez de fixas. Este artigo argumenta que em situações de pós-conflito tais como a da África do Sul pós-apartheid, onde a linha divisória entre perpetuadores e vítimas tende a se esvaecer, a linha divisória entre opressor e oprimido torna-se menos clara e escorregadia. $\mathrm{O}$ artigo propõe a adoção de uma pedagogia pós-crítica alternativa que possa transcender tais fronteiras rígidas.

Palavras-chave: Pedagogia pós-crítica; mitos repressivos; pedagogia do oprimido; teatro do oprimido.

\section{Abstract}

While a number of exponents of critical pedagogy argue that it is an appropriate framework for challenging dominant discourses that seek to perpetuate oppressive power relations and social inequalities, others have begun to counter-argue that it still remains a "pedagogy of the oppressed". By continuing to construct the "world" as divided between binary oppositions of race, class, gender and ethnicity, critical pedagogy tends to gloss over more complex relations of power in which these categories are fluid than fixed. South Africa, where the dividing line between perpetrators and victims tends to be blurred, the dividing line between oppressor and oppressed becomes les clear and more slippery. The article proposes the adoption of an alternative post-critical pedagogy that can transcend such rigid boundaries.

Keywords: Post-critical pedagogy; repressive myths; pedagogy of the oppressed; theatre of the oppressed.

ISSN: 1414.5731

\footnotetext{
${ }^{1}$ Este artigo está baseado em uma comunicação apresentada na Drama for Life Africa Research Conference (DFL), intitulada "Building a Critical Pedagogy in Applied Drama and Theatre for Higher Education in Africa", ocorrida na Universidade de Witwatersrand, Johannesburg, África do Sul, 18-19 de novembro de 2011.

${ }^{2}$ Kennedy C. Chinyowa é chefe da Divisão de Arte Dramática e Senior Lecture em Drama e Teatro Aplicado na Universidade de Witwatersrand em Johannesburg, África do Sul. Anteriormente foi Pesquisador Pós-Doutor na Universidade de KwaZulu-Natal (2006-2007) e Universidade Tshwane de Tecnologia (2008-2009). Ensinou também em
}

outras universidades, como a Universidade de Zimbabwe e foi professor visitante na Universidade de Griffith (Austrália, 2001-2005), onde obteve seu doutorado em Teatro para o Desenvolvimento.

${ }^{3}$ Beatriz Ângela Vieira Cabral, professora Adjunta da Universidade do Estado de Santa Catarina (UDESC), Florianópolis, SC, Brasil, bcbiange@gmail.com, desenvolveu pesquisas nas áreas de impacto e risco no ensino do teatro, análise da recepção em drama, e, atualmente ' $O$ Jogo da Interpretação: subjetividades em cena e criação em grupo'. Foi bolsista de Produtividade e Pesquisa CNPq no triênio 2011-2013. 


\section{Introdução}

O desafio para o drama e o teatro aplicado, como uma disciplina emergente dentro da academia reside em encontrar uma perspectiva crítica apropriada para interrogar tal pedagogia baseada na prática. Esta disciplina de múltiplas faces requer uma abordagem interdisciplinar que possa 'falar' para práticas educacionais planejadas para unir teoria e prática. Os processos de aprendizagem transformadores implantados através do drama e do teatro aplicado exigem uma igualmente libertadora pedagogia que não crie divisões entre o 'opressor e o 'oprimido'.

Proponentes da pedagogia crítica, tais como Paulo Freire (1970), Peter McLaren (1998), Henry Giroux (1995) e Ira Shor (1992), concordam que esta oferece um enquadramento apropriado para criticar os discursos dominantes que procuram perpetuar as relações de poder e desigualdades sociais operando em diferentes espaços privados e públicos. O objetivo principal da pedagogia crítica é fortalecer indivíduos e comunidades para compreender a ligação entre conhecimento, história e poder, e para usar tal conhecimento para resistir às ideologias e estruturas dominantes (Darder et al, 2003).

Entretanto, como Jonathan Jansen (2009) argumenta, embora a pedagogia crítica se preocupe com a transformação das relações de poder opressivas, ela ainda permanece uma 'pedagogia do oprimido'. Ela constrói o 'mundo' como dividido entre preto e branco, masculino e feminino, rico e pobre, hetero e homossexual, eu e o outro. Ela passa por cima de relações mais complexas de poder nas quais estas categorias binárias são fluídas em vez de fixas. Este artigo argumenta em prol de uma pedagogia pós-crítica que possa transcender tais fronteiras rígidas. A partir de intervenções de teatro aplicado desenvolvidas com estudantes da Universidade de Witwaterstand, o artigo argumenta que os espaços institucionais 'pós-conflito' são locais divididos onde histórias e memórias de confronto entram em choque. O desafio é criar espaços dialógicos onde ambos 'opressor' e 'oprimidos' possam se identificar, envolver com, interrogar e problematizar seus conhecimentos sem medo de julgamento, demissão ou censura.

\section{Drama e teatro aplicado como pedagogia crítica}

Leigh Anne Howard (2004) argumenta que a pedagogia crítica marca a transição da ideologia para a práxis ao associar-se a atividades baseadas em performance. Tal combinação leva à formação de uma comunidade que fortalece os participantes ao gerar entendimento crítico e criar espaços de aprendizagem transformadora. $\mathrm{Na}$ pedagogia crítica os participantes não estão apenas envolvidos no processo educacional; eles estão implicados na concretização de conhecimento, poder, identidade, representação e agência. Parafraseando Augusto Boal (1979) a respeito do potencial transformador do Teatro do Oprimido (TO), se os participantes podem atuar, em vez do artista em seu lugar, aquela ação na ficção teatral irá fazer com que atuem eles próprios em ações similares na vida real. 
Se vista pela perspectiva da interrogação de oposições binárias tais como gênero, raça, classe e etnia, a pedagogia crítica busca transformar os participantes em sujeitos em vez de objetos da história, a fim de dar-lhes autoridade de expressar a si próprios através de suas próprias vozes. Tomando gênero como foco, Judith Butler (1988) enfatiza que gênero não é um dado biológico, mas sim uma construção social instituída através de ações performativas tais como linguagem, gesto, movimento e outras atividades simbólicas. Butler vai além neste argumento e afirma que se a identidade do gênero é instituída através de atos performativos, então a transformação do gênero pode ser obtida através da desconstrução de tais atos. Por extensão, pode-se argumentar que se a identidade do gênero pode ser reconstruída, o mesmo se aplica a outras construções de alteridade, tais como raça, classe e etnia.

Entretanto, outro exemplo pode ser tomado do argumento de Daniel Banks (2006) sobre teoria racial. Ele afirma que a raça surge de um processo ideológico que nomeia indivíduos como sujeitos constituídos. Assim como o gênero, a raça é institucionalizada através de atos performativos que se apresentam como verdades hegemônicas. Assim raça, também, é um constructo social que pode ser desconstruído e reconstruído diferentemente. Como acentua Banks:

O que precisa ser feito para romper [...] racialização é substituir um modo de organização alternativo, para demonstrar a disjunção entre significante e significado ... Em outras palavras, a corrente de representações que concretiza ficções ou verdades parciais em identidades raciais fixas precisa ser desperformatizada (Banks, 2006, p. 188).

Banks (2006) opta por um novo sistema de representação que tem um vocabulário específico para as experiências dos sujeitos performativos, permitindo múltiplas possibilidades e criando espaços de inclusão em vez de exclusão. Como um modo interativo de pedagogia, o campo do drama e do teatro aplicado opera como um 'sistema de representação' incorporado com a capacidade de criar espaço para 'sujeitos performativos' se engajarem com, e interrogarem, espaços de alteridade.

\section{Armadilhas da pedagogia crítica}

O movimento da pedagogia crítica tem recebido críticas crescentes por sua tendência a encobrir questões complexas sobre diferença, voz, empoderamento, diálogo, agência e transformação. Reconhecidamente, seus defensores convictos continuam a argumentar em termos de oposições binárias, reafirmando que:

O compromisso e a intenção subjacente da pedagogia crítica continuarão enquanto houver aqueles que são forçados a existir em condições de sofrimento e alienação, e aqueles que se recusam a aceitar tais condições como uma evolução natural da humanidade (Darder et al, 2003, p. 21).

Entretanto, tais argumentos estão sendo contestados pelo fracasso aparente da pedagogia crítica lidar com narrativas pessoais e circunstâncias histó- 
ricas que afetam seus sujeitos. Por exemplo, Darder et al. (2003) afirmam que a linguagem obscura da pedagogia crítica feminista tem criado uma nova forma de opressão para aqueles que se encontram às margens de tal discurso intelectual. O discurso feminista não apenas permanece inacessível para muitos daqueles aos quais se dirige, mas também falha ao se engajar com outras questões de contestação e luta. Entretanto, enquanto Darder e colegas criticam as contradições aparentes no discurso feminista, eles não parecem estar conscientes das implicações mais amplas do movimento da pedagogia crítica. Como David Livingstone (1987) ressalta, se a pedagogia crítica pretende cumprir seu mandato de criar mudança social verdadeiramente criativa, ela precisa não apenas se engajar com níveis mais complexos de formações ideológicas, mas também com as dinâmicas de poder cultural.

Talvez Elizabeth Ellsworth (1989) coloque o desafio mais sério à pedagogia crítica ao considerar termos tais como 'empoderamento', 'voz', 'diálogo' e 'consciência' como mitos repressivos. Ela explica que quando participantes querem colocar estes termos em prática, eles geralmente acabam por perpetuar eles próprios as mesmas relações de dominação contra as quais estão lutando. Ellsworth argumenta que narrativas de opressão são parciais, incompletas e limitadas no sentido em que projetam os interesses de um lado (o oprimido) sobre outros (os opressores). Os participantes são levados a equiparar um entendimento da construção social da realidade por grupos dominantes, com transformação. Por esta razão, as estratégias implantadas para dar voz aos marginalizados geralmente criam a ilusão de liberação enquanto reforçam, ou mesmo pioram as estruturas opressivas. Há chamadas para uma pedagogia alternativa que seja responsiva às histórias, sonhos e experiências dos participantes (Giroux, 1995), Jansen (2009) tem argumentado a favor de uma pedagogia pós-crítica que transcenda os limites da pedagogia crítica - onde, por exemplo, estudantes árabes e judeus em Israel, estudantes católicos e protestantes na Irlanda, estudantes Hutu e Tutsi em Rwanda, e estudantes brancos e negros na África do Sul pós-apartheid possam se engajar livremente no mesmo espaço dialógico.

\section{Em direção a uma pedagogia pós-crítica}

Em uma típica ilustração de 'mitos repressivos' associados com pedagogia crítica, Jansen (2009) dá um exemplo de um tour de ônibus com estudantes da Universidade de Pretoria a dois monumentos rivais representando diferentes lutas na história da África do Sul. A primeira visita foi ao Voortrekker Monumento em Pretoria, que comemora a Guerra Anglo-Boer (1902), um símbolo do nacionalismo afrikaner e da luta pela supremacia racial. A segunda visita foi ao Apartheid Museu em Johannesburg, que representa a luta nacionalista africana para libertação do apartheid. Durante uma sessão de comentários com os estudantes, após o tour, Jansen destaca os comentários de uma estudante afrikaner perguntando ao palestrante insuspeito, 'Foi certo e bom nos levar ao Museu do Apartheid; agora me diga, quando nós construiremos um museu para todos os brancos assassinados nas fazendas da África do Sul depois de 1944?' (in Jansen 
2009, p.149). Foi evidentemente difícil responder à pergunta da estudante nestas circunstâncias. Ela demonstrou o peso da memória da estudante sobre um passado glorioso pleno de conquistas nacionalistas dos afrikaners. O Museu do Apartheid foi assim a antítese das coisas que ela ainda conserva com carinho em sua memória. Eu interpreto a raiva contida em sua fala como a expressão de profundo pesar sobre o que ela e seus semelhantes haviam perdido, ironicamente em nome da liberdade e da democracia. Entretanto, Jansen (2009) observa que os estudantes negros reagiram ao Voortrekker Monument com sentimentos de indiferença e contentamento. O apartheid não estava mais no poder, portanto o monumento havia perdido sua autoridade representacional uma vez que os pretos estavam agora no controle. Em essência, o tour de ônibus serviu pra reforçar em vez de reduzir o fosso racial entre os estudantes brancos e negros.

A pedagogia pós-crítica busca interrogar espaços de alteridade sem reproduzir narrativas que são opressivas para as narrativas de outros. Como Jansen (2009, p.151) salienta ainda, os espaços institucionais pós-conflito são espaços divididos, onde histórias e memórias em disputa criam profundos e complexos desafios. A primeira tarefa daqueles em posição de autoridade é entender os efeitos social, psicológico e emocional das memórias carregadas pelos diferentes grupos raciais e étnicos. A segunda tarefa é criar espaços seguros dentro dos quais ambos os grupos possam falar abertamente sem medo de julgamento, represália ou censura. O uso do drama e teatro aplicados como um modo de pedagogia performativa pós-crítica cria espaços dialógicos que permitem que alunos identifiquem, engajem com, e interroguem seus conhecimentos problemáticos. Ao contrário de legalistas e outros procedimentos formais disciplinares, drama e teatro aplicados podem permitir espaço para engajamento interpessoal, em vez de confrontações diretas que são capazes de acelerar o antagonismo, a agressão e o medo.

Examinarei agora uma oficina de drama aplicado que foi realizada pelo projeto Acting Against Conflict (Atuando contra Conflitos) com estudantes da Universidade de Witwatersrand para mostrar como a pedagogia pós-crítica pode preencher as lacunas deixadas pela pedagogia crítica. O grupo de facilitadores do projeto trabalhou em colaboração com unidades de outra universidade tais como Wits Transformation Office (Escritório de Transformação Wits), Counselling and Careers Development Unit - CCDU (a Unidade de Aconselhamento e Desenvolvimento Profissional) e o Drama for Life Program (Programa Drama para a Vida), desde 2009. A maior parte das intervenções na oficina usou estratégias do Teatro do Oprimido, de Augusto Boal, para criar espaços estéticos para estudantes se engajarem com problemas relacionados com conflitos tais como assédio sexual, preconceito racial e étnico.

A oficina selecionada aconteceu em março de 2011 como parte de uma colaboração em andamento entre a Divisão de Trabalho Social, baseada na Escola de Desenvolvimento Humano e Comunitário, e o projeto Acting Against Conflict. Trinta estudantes cursando um curso de 'Abordagens Psicossociais aos Direitos Humanos', ministrado por Linda Smith e Peace Kiguwa o frequentaram. Através de e-mail, Peace Kiguwa me explicou que o curso pretendia desafiar os alunos a 
pensar criticamente sobre os direitos humanos dentro de um contexto mais amplo de luta política e justiça social. Para isto, os estudantes foram introduzidos a teóricos do movimento da pedagogia crítica, tais como Frantz Fanon, Ngugi wa Thiong'o, Paulo Freire e Augusto Boal. A oficina pretendia não só preencher a lacuna entre teoria e prática, mas também propiciar aos estudantes a atuação em direitos humanos. Como Daniel Banks (2006, p.190) argumenta, intervenções performáticas podem alterar a percepção de identidades previamente articuladas. $O$ que emerge pode ser a substituição de identidades previamente inscritas (assentadas) por um sentido de identidades reconstruídas.

Após jogos de aquecimento preliminares e exercícios para romper a familiaridade e construir a credibilidade do universo ficcional, eles foram divididos em dois grupos. Os dois facilitadores do projeto instruíram os estudantes a compartilhar histórias baseadas quer em experiências pessoais ou observações de conflitos raciais ou étnicos. Jan Cohen-Cruz (2006) considera que a força da narração de histórias está enraizada na autoridade da experiência e na capacidade de colocar mesmo os indivíduos menos fortes na posição de sujeitos em vez de objetos. A própria ação de contar sua história em público é um movimento em direção à agência, poder e autoridade. Cada grupo foi então solicitado ou a escolher uma das histórias ou a compor suas histórias em uma única história a ser apresentada para o outro grupo. As histórias tornaram-se blocos de sustentação de um teatro-fórum baseado em diálogos nos quais os espectadores foram transformados em atores - o que Boal denominou 'spec-actors'. Quando as histórias pessoais são representadas, elas não pertencem mais ao narrador original, mas tornam-se objeto de identificação para os outros. Boal (1995, p. 45) afirma que teatro é o domínio da primeira pessoa do plural. Embora ele possa começar com uma história individual, ele adquire um caráter simbólico ao tornar-se uma questão de interesse público. Os grupos finalmente representaram contextos nos quais subtemas significantes emergiram - tais como brancura versus negritude, racismo e xenofobia linguística, para mencionar apenas alguns. Eu focalizarei o subtema brancura versus negritude, uma vez que ele tendeu a ser mais dominante que os demais.

A história apresentada pelo primeiro grupo claramente demonstrou a força contida naquilo que Jansen (2009) denomina 'conhecimento no sangue' - isto é, o conhecimento adquirido que é introjetado nas mentes e corações dos jovens através de transmissão de geração a geração. A performance inicia com duas crianças negras sentadas no banco de uma farmácia. As crianças estão na fila para serem atendidas quando uma mulher branca entra na cena. A mulher branca (Mulher 1 ) ordena que as crianças se movam para o final da fila. Duas mulheres negras então entram na farmácia e uma delas (Mulher 2) pergunta às duas crianças se elas estão na fila. A cena se desenvolve da seguinte maneira:

(Cena em uma farmácia)

Mulher 2: (pergunta às crianças) Olá, vocês meninas, estão na fila?

(as crianças fazem um gesto para os assentos próximos a elas) 
Mulher 1: (interrompe) Você sabe, eu não pretendo interromper. É apenas para que estas crianças vejam claramente que as pessoas precisam ficar na fila.

(as crianças guris se entreolham)

Mulher 2: Está OK, deixa as crianças ficar aí ... nós acabamos de chegar.

Mulher 1: Não ... não ... não, vocês pretos serão sempre pretos, ... incompetentes - na realidade tão sem consideração.

Mulher 2: (surpresa) Com licença! O que tem incompetência a ver com isso?

Meninas: (entre si) O que significa incompetência?

Mulher 1: Você sabe, fazem 27 anos ... e ainda os pretos não ...

Mulher 2: O que? Tire os pretos fora disso ...

Mulher 1: Eu tenho trabalhado neste área deste sempre. Você não pode me dizer nada. Eu tenho visto todo tipo de pessoas. É a incompetência que me incomoda. Eu sou racista naturalmente você diria - está bem, mas eu certamente não vou mudar minha vida.

(Extrato de vídeo clip)

A cena acima sintetiza a natureza do 'conhecimento no sangue', e como ele afeta a compreensão e o relacionamento de brancos e pretos da geração pós-apartheid na África do Sul. Jansen (2009) argumenta que não importa quão profundamente enraizado tal conhecimento possa estar, ele deveria ser sujeito à interrogação. A cena dramatiza a política subjacente ao 'ser branco' como uma ideologia da supremacia que advogava a separação das raças sob o apartheid. $\mathrm{Na}$ época em que o Partido Nacional Afrikaner chegou ao poder, em 1948, a política de apartheid havia se tornado sinônimo de supremacia branca. Em contraste, a negritude era igualada á escravização, exploração e opressão. Bernard Magubane (2007) argumenta que a ideia da superioridade branca (ou 'brancura') e inferioridade negra (negritude) continuou a ser recriada e atualizada na prática cotidiana. Assim a cena ilustra não apenas a carga da brancura e negritude transmitida através da 'identidade no sangue', mas também como a oposição binária de 'perpetuadores' e 'vítimas' se estendeu ao período pós-apartheid.

$\mathrm{Na}$ linha da técnica de 'atores-espectadores' de Augusto Boal (1979), os facilitadores convidaram outro participante para substituir a Mulher 2 como o personagem oprimido a fim de modificar o resultado da cena fórum. A intervenção no fórum funcionaria como um espaço estético para mudar a opressão ao permitir aos alunos debater e experimentar alternativas. Com este intuito, dois 'atores -espectadores' entraram no palco para substituir o protagonista numa tentativa de transformar a imagem de 'brancura' apresentada pela Mulher 1, representante do opressor. A primeira intervenção do ator-espectador (Participante 1) foi agressiva e violenta como se segue: 
(o participante vai ao palco. O facilitador explica aos atores que eles vão fazer a cena novamente. O participante-transformado-em-ator ocupa o lugar da mulher negra)

Mulher 1: Sinto interromper, mas eu já disse a estes garotos que se movessem. Ah! Pretos são pretos e serão sempre incompetentes.

Participante 1: O que? O que você quer dizer com pretos? Ei, eles são crianças!

Mulher 1: Bem, em meus 27 anos de experiência na área médica ...

Participantes 1: Você pare exatamente aí (ele se aproxima fisicamente da Mulher 1). Quem você pensa que é? (apontando e cutucando o peito da $\mathrm{Mu}$ lher 1). Você não tem o direito de dizer isto para mim ou para qualquer pessoa! Na realidade apenas desapareça da minha frente! (ela continua a empurrar a mulher 1).

Mulher 1: Me desculpe? (ficando nervosa e empurrando a outra para trás)

(extrato de vídeo clip)

A intervenção do primeiro participante não apenas demonstra o poder do 'conhecimento no sangue', mas também expõe as pretensões dialógicas da pedagogia crítica. Mostra como a pedagogia crítica está severamente limitada nas situações pós-conflito para fazer sentido de conhecimentos problematizados, e transformar aqueles que carregam tal conhecimento nos dois lados da divisão racial. O mundo permanece dividido entre 'opressores' e 'oprimidos', 'perpetuadores' e 'vítimas', e neste caso entre 'brancura' e 'negritude'. Se o derradeiro objetivo do teatro fórum é estimular um debate teatral - transformar espectadores em protagonistas que podem mudar da opressão para a liberação - a intervenção do primeiro participante foi uma clara negação do diálogo como um processo de empoderamento e transformação.

Críticas da pedagogia crítica (Ellsworth, 1989; Gur Ze've, 1998) argumentam que ela negligencia a vulnerabilidade mútua compartilhada por ambos perpetuadores e vítimas. Jansen (2009) afirma que as atitudes do apartheid podem ser rastreadas a partir do aumento do nacionalismo afrikaner como um resultado do sofrimento dos afrikaners em campos de concentração durante a Guerra dos Bôeres. Por isso ambos os lados da divisão racial carregam a carga de histórias e memórias de disputa. Para tais sociedades de pós-conflito, a opção é criar espaço para grupos rivais compartilhar seus conhecimentos problemáticos. Como observa C.V. Kwenda (2003), o princípio de mútua vulnerabilidade requer uma pedagogia mais humanizadora que torne possível confrontar, reconhecer, interrogar e transcender atitudes, valores e crenças adversárias. Em alguma medida, esta pedagogia foi demonstrada pela intervenção do segundo spect-ator (Participante 2):

(o curinga chama o participante para assumir o papel da mulher negra, e a cena é reapresentada.)

Mulher 1: Estas meninas são tão incompetentes que não entendem uma simples instrução. Ah! Pretos serão sempre pretos! 
Participante 2: O que você quer dizer quando você diz 'pretos serão sempre pretos'?

Mulher 1: Eles são incompetentes!

Participante 2: Você está me dizendo que eu sou incompetente?

Mulher 1: Você é tão experiente como eu? Você tem 27 anos na área médica?

Participante 2: O que eu faço é irrelevante. O que você está dizendo agora é inconstitucional. Você não precisa gostar disso, mas nós precisamos aprender a viver juntos. Eu aceito você. Eu não preciso gostar de você, mas eu aceito você.

(extrato de vídeo clip)

\section{Implicações para a pedagogia do drama e teatro aplicado}

Uma pedagogia crítica de abordagens de drama e teatro aplicado, tal como o Teatro do Oprimido de Boal revela uma série de 'mitos repressivos' que não são favoráveis à uma boa prática pedagógica. Na realidade, críticos identificaram lacunas no arsenal de técnicas de Boal que precisam ser abordadas para evitar perpetuar as mesmas desigualdades, injustiças e opressões que o campo do drama e do teatro aplicado pretende focalizar. Por exemplo, a poética do oprimido, de Boal, tem sido vista mais como experimental e transitória do que como prática e libertária (Burton 2006). Os curingas são geralmente considerados como tendo total controle em relação tanto aos espectadores quanto aos spec-actors, enquanto a poética tende a ser restrita à 'pedagogia do oprimido' em detrimento da 'pedagogia do opressor'. Por isso, o Teatro do Oprimido encobre complexidades inscritas em situações de 'poder e autoridade', submissão e subordinação, 'desigualdade e injustiça', e outras polaridades. Boal (1992) trata o 'opressor' como um sistema dominante despojado de qualidades humanas. $E$ se o sistema dominante for substituído, como em situações pós-conflito? De certa maneira, a pedagogia crítica torna-se insuficiente para lidar com as complexidades inerentes que se escondem nas situações contraditórias de opressão, tais como pretos colaborando com o sistema do apartheid, brancos colaborando com pretos durante a luta da libertação, pretos cedendo a um racismo inverso após a luta, e a sutil presença do 'opressor' dentro do 'oprimido'.

Os praticantes do drama e do teatro aplicados precisam considerar mudanças em direção a uma pedagogia alternativa que não dilua as contradições, complexidades e diferenças que ainda existem em espaços institucionais pósconflito. Este artigo argumentou, portanto, em favor da adoção de uma pedagogia pós-crítica dentro de contextos educacionais pós-conflito. Como acentua Jansen (2009) o que os pedagogos críticos, tais como drama e teatro educadores, enfrentam no rescaldo dos conflitos cataclísmicos como o apartheid não são tanto os sistemas opressivos, mas seres humanos reais carregando memórias, histórias e experiências rivais. A pedagogia pós-crítica é uma tentativa de lidar com tais conhecimentos e experiências problematizadas. A opção para a 
pedagogia do drama e do teatro aplicados é encontrar formas de interromper tais memórias rivais através da 'dissonância pedagógica' (Jansen 2009:154). Da mesma forma que as identidades binárias são socialmente construídas através de experiências vividas, elas também podem ser desconstruídas através de uma pedagogia humanista mais balanceada e menos unilateral.

\section{Referências}

BANKS, D. "Unperforming 'Race': Strategies for Reimagining Identity", in J. Cohen-Cruz and M. Schutzman (eds.), A Boal Companion: Dialogues on Theatre and Cultural Politics. New York: Routledge, 2006, pp 185-98.

BOAL, A. Theatre of the Oppressed. London: Pluto Press, 1979.

Games for Actors and Non-Actors. London: Routledge, 1992.

Rainbow of Desire: The Boal Method of Theatre and Therapy. London:

Routledge, 1995.

BURTON, B. 'Enhanced Forum Theatre', Drama NSW JEDA Journal 13: 1, 2006, pp. 1-7.

BUTLER, J. 'Performative Acts and Gender Constitution: An Essay in Phenomenology and Feminist Theory', Theatre Journal, 40: 4, 1988, pp. 519-31.

COHEN-CRUZ, J. 'Redefining the Private: From Personal Storytelling to Political Act', in J. Cohen-Cruz and M. Schutzman (eds), A Boal Companion: Dialogues on Theatre and Cultural Politics. London: Routledges, 2006, pp. 103-12.

DARDER, A., Baltodano, M. and Torres, R. (eds), (2003), The Critical Pedagogy Reader. London: RoutledgeFalmer, 2003.

DENZIN, N. K. Performance Ethnography: Critical Pedagogy and the Politics of Culture. Thousand Oak, CA: Sage, 2003.

ELLSWORTH, E. 'Why Doesn't It Feel Empowering? Working Through the Repressive Myths of Critical Pedagogy', Harvard Educational Review, 59:3, 1989, pp. 297-324.

FREIRE, P. Pedagogy of the Oppressed. Harmondsworth: Penguin, 1970.

GIROUX, H. Border Crossing: Cultural Workers and the Politics of Education. London: Routledge, 1995.

Gur-Ze'ev, I. 'Toward a Non-repressive Critical Pedagogy', Educational Theory, 48:4, 1998, pp. 463-87. 
HOWARD, L.A. 'Speaking Theatre/Doing Pedagogy: Re-visiting Theatre of the Opressed', Communication Education, 53: 3, 2004, pp. 271-33.

JANSEN, J. 'On the Clash of Martyrological Memories', Perspectives in Education, 27:2, 2009, pp. 147-57.

(2011) We Need to Talk Northcliff, SA: Bookstrom and Pan Macmillan. Kiguwa, P. (2010), 'Evaluative Report on Guest Input by the Drama Department', School of Human and Community Development, University of the Witwatersrand.

KWENDA, C.V. 'Cultural Justice: The Pthway to Reconciliation and Social Cohesion', in D. Chidester, P. Dexter and W. James (eds), What Holds Us Together: Social Cohesion in South Africa. Cape Town: HSRC, 2003. 